\title{
Airway hyperresponsiveness in the elderly: prevalence and clinical implications
}

\author{
N. Scichilone, M. Messina, S. Battaglia, F. Catalano and V. Bellia
}

ABSTRACT: Airway hyperresponsiveness is associated with an increased risk of developing respiratory symptoms. The assessment of airway hyperresponsiveness can provide valuable information regarding the natural course of respiratory diseases. However, little information is available for populations of more advanced age, and data are conflicting.

It was assessed whether age influences the occurrence of airway hyperresponsiveness by reviewing those studies that specifically addressed this issue, and attempting to identify the factors responsible for discrepancies between studies.

Eighteen studies, published between 1983 and 2002, are included in this review. Overall, the results of the analysis are in favour of a positive association between age and airway hyperresponsiveness, the prevalence of which appears to increase in the elderly. The most important determinants were reduced lung function, probably due to geometric factors, and a history of smoking, primarily because of the length of exposure, although acute effects were also demonstrated. Atopy should also be considered as an independent determinant of airway hyperresponsiveness in the elderly population. In addition, inflammatory and neuronal mechanisms could be involved. Finally, the role of sex requires further investigation.

Assessing the impact of age on the occurrence of airway hyperresponsiveness has important implications: the age-associated alterations to the lung provide a model for evaluating the contribution of structural changes to the pathogenesis of airway hyperresponsiveness. From a clinical standpoint, evaluation of the magnitude of airway hyperresponsiveness could permit the early identification of individuals who are at risk, even at more advanced age. Assessment of airway hyperresponsiveness in the aged should be considered as an additional tool in the diagnostic work-up in the subset of elderly subjects with long-term smoking exposure and/or documented atopy.

\section{KEYWORDS: Ageing, airway hyperresponsiveness}

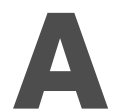

irway hyperresponsiveness to nonspecific external stimuli is a common feature of asthma and is responsible for most of the clinical features of this disease [1]. Exaggerated airway responses to bronchoconstrictors can also be detected in a significant proportion of individuals with no history of respiratory diseases or complaints of respiratory symptoms [2]. The clinical significance of this phenomenon is still a matter of debate. Asymptomatic airway hyperresponsiveness could precede the occurrence of asthma [3], perhaps representing a condition of transition from the lack of symptoms to the asthmatic phenotype. In addition, longitudinal studies have demonstrated that increased airway responsiveness is associated with an accelerated decline in lung function [3-8], not only in asthmatic subjects but also in individuals with no respiratory symptoms. Therefore, the assessment of the severity of airway responsiveness could provide valuable information regarding the natural course of respiratory diseases. It should be emphasised, however, that this phenomenon has been evaluated mainly among adolescents or young adult individuals, and little information is available for populations of more advanced age.

Two studies have confirmed that airway hyperresponsiveness is far more common amongst the elderly than previously recognised $[9,10]$, with prevalence rates ranging $29-43 \%$. Measurement of bronchial responsiveness is feasible and clinically valuable in elderly subjects [11]: the
AFFILIATIONS

Institute of Respiratory Diseases,

University of Palermo, Palermo, Italy.

CORRESPONDENCE

N. Scichilone

Istituto di Medicina Generale e

Pneumologia

Cattedra di Malattie dell'Apparato

Respiratorio

Università di Palermo

via Trabucco 180

90146 Palermo

Italy

Fax: 390916891857

E-mail: n.scichilone@libero.it

Received:

July 032004

Accepted after revision:

August 132004 
accepted concepts that airway hyperresponsiveness in the geriatric population is associated with accelerated decline in forced expiratory volume in one second (FEV1) [12] and with newly diagnosed cases of asthma [13] highlight the importance of assessing this phenomenon in those of more advanced age. Elderly individuals with asthma are one of the groups affected by disproportionate morbidity from this disease [14]. Asthma in the elderly is characterised by an overall impairment in quality of life [15]; even more importantly, asthma-related mortality in this age group has steadily increased [16]. Thus, early detection of airway hyperresponsiveness in the elderly may help to reduce respiratory morbidity in the elderly.

Assessing the impact of ageing on the occurrence of airway hyperresponsiveness has important implications from the point of view of pathogenesis and diagnosis. As regards the former, since ageing is associated with structural and physiological alterations to the lung $[17,18]$, an understanding of the contribution of these abnormalities to the hyperresponsive phenotype could help in elucidating the underlying mechanism(s). Conversely, since asthma in the elderly is often underdiagnosed and undertreated [13, 19], early detection of airway hyperresponsiveness in these individuals could permit the identification of elderly asthmatics at an earlier stage so as to optimise the treatment of this disease. Finally, since, as previously indicated, increased airway responsiveness has been associated with an accelerated decline in lung function $[3-6,8]$, it would be intriguing to determine whether airway hyperresponsiveness represents the cause, rather than the consequence, of such decline.

Based on the above observations, it is reasonable to try to address the question of whether age per se influences airway hyperresponsiveness. The present review attempts to assess the relationship between ageing and the prevalence of airway hyperresponsiveness, and to identify any potential clinical implications arising from this relationship.

\section{METHODS}

In order to determine the impact of age on airway responsiveness, a systematic literature search using MEDLINE for the years 1966-2004 was performed. The search strategy initially included the Medical Subject Heading (MeSH) terms "bronchial hyperreactivity", "bronchial provocation test", "bronchoconstrictor agents", "methacholine chloride" and "histamine", in combination with "age factors", "age distribution", "aging" and "aged". Since "aged", as a MeSH term, defines a person aged 65-79 yrs, the string "aged, 80 and over" was also applied. Furthermore, the terms "bronchial hyperresponsiveness", "airway hyperresponsiveness", "elderly" and "population" were used. The search was restricted to human studies and articles published in the English language. Since the term "asthma" may have been used in some studies to describe a condition of increased responsiveness of the airways, the literature search was performed again, adding to the original string the MeSH term "asthma" with the subheadings "diagnosis" and "epidemiology". The reference lists from relevant eligible studies were also hand-searched. All articles that were identified were examined for eligibility by three investigators independently (N. Scichilone, S. Battaglia and M. Messina); any disagreement was discussed in a consensus form that included a senior investigator (V. Bellia).

\section{Selection and study characteristics}

The ideal study aimed at evaluating age-related modification of bronchial responsiveness should assess the outcome longitudinally; however, data based on longitudinal studies are scarce. Most studies assessing the relationship between airway hyperresponsiveness and age are cross-sectional; this limits the conclusions of the current review in that period and cohort effects cannot be accounted for. Conversely, crosssectional studies avoid the effect of variability of the bronchoprovocation test that, in longitudinal investigation, may lead to difficulty in differentiating signal from noise. Cross-sectional studies on the general population usually include individuals with chronic respiratory symptoms, thus accounting, on average, for $\sim 5 \%$ of asthmatics and $\sim 10 \%$ of subjects with chronic obstructive pulmonary disease. This is of particular importance, since analysis of the impact of ageing should be able to discriminate this from the time-related effects of the disease. However, the role of respiratory diseases or symptoms was taken into account, in the studies that were considered, using an appropriate statistical analytical approach (i.e. logistic multivariate analysis) or, alternatively, subjects with respiratory diseases were subsequently excluded from the primary analysis.

Studies were eligible if they fulfilled the following criteria: 1) use of a standardised nonspecific bronchial challenge test; 2) inclusion of large randomly selected study populations; and 3) extension of the assessment to subjects aged $>65$ yrs. Therefore, studies in which a bronchoprovocation test that employed a nonspecific stimulus other than histamine or methacholine (e.g. cold air) was performed, studies with a small number of selected subjects, and studies performed only on children or adolescent and young adult populations were excluded.

For each eligible study, the reported data on sample size, age range, criteria for diagnosis of airway hyperresponsiveness, prevalence of airway hyperresponsiveness in the various age groups and determinants of hyperresponsiveness were recorded. For the purpose of the present review, the quantitative criteria used in each study to define airway hyperresponsiveness need to be carefully evaluated. In the majority of the studies, airway hyperresponsiveness was defined as the dose (or concentration (PC20)) of methacholine or histamine causing a $20 \%$ fall in FEV1 from baseline or postdiluent values, or by using the corresponding cut-off values of the linear dose-response slope (i.e. the slope of a line connecting the origin with the last point of the spasmogen dose-response plot). In one study, a condition of hyperresponsiveness was established on the basis of a $15 \%$ drop in FEV 1 from baseline [20], whereas, in the studies of RIJCKEN and coworkers $[21,22]$, the chosen cut-off was a reduction in FEV1 of $10 \%$ from baseline following histamine administration.

\section{RESULTS}

A summary of the process of selection is shown in figure 1 . Due to the restrictive criteria employed to select the articles, only 18 studies, published between 1983 and 2002, were included in the present review (table 1). The vast majority of 


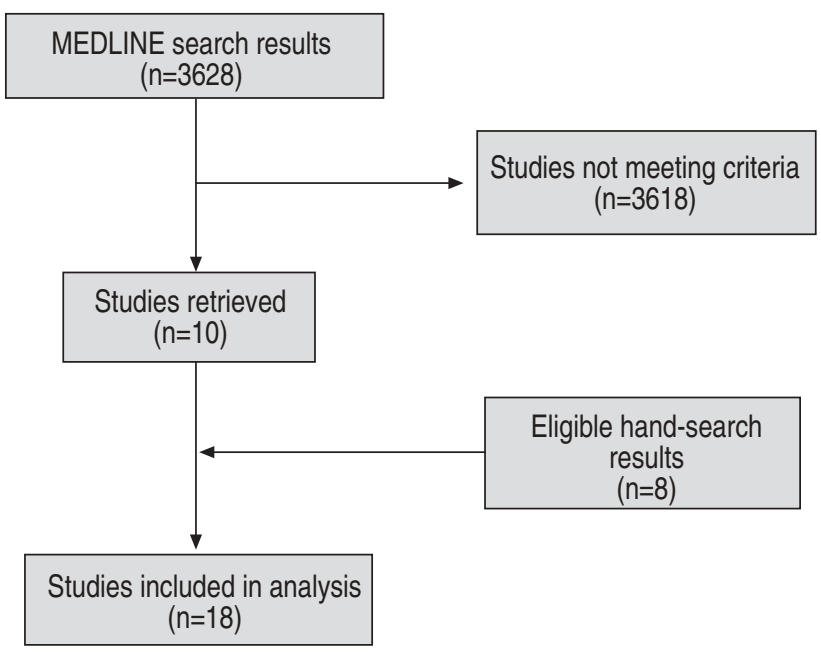

FIGURE 1. Description of selection process.

studies were excluded because the population examined was restricted to adolescents or young adults (e.g. the investigations based on the population from the European Community Respiratory Health Survey (ECRHS)), or consisted only of asthmatics. Analysis of the selected studies has yielded conflicting results. The majority of the studies demonstrated a positive relationship between ageing and airway responsiveness in that age was found to be an independent correlate of increased airway responsiveness. However, other studies showed either a negative correlation or a lack of correlation between ageing and airway hyperresponsiveness. As discussed below, many reasons can be put forward to explain these discrepancies.

\section{Airway hyperresponsiveness increases with ageing}

One of the first studies aimed at addressing the relationship between age and airway hyperresponsiveness was published in 1985 by Hopp et al. [23]; this cross-sectional study was carried out on a sample of 148 nonsmoking healthy subjects, with age ranging 5-86 yrs and $11(7.4 \%)$ subjects aged $>67$ yrs. These individuals formed part of a larger study of the natural history of asthma conducted during 1972-1983. In this population, exaggerated bronchoconstrictive responses to spasmogen, expressed as the area under the dose-response curve, were found to be more prevalent in the youngest and oldest study groups, as opposed to the intermediate age groups. This finding was put forward as suggesting that age has a significant influence on the occurrence of airway hyperresponsiveness, independent of respiratory symptoms.

As stated above, assessment of the relationship between airway hyperresponsiveness and age should ideally be performed in a longitudinal study setting. The influence of age on airway responsiveness has been widely investigated in the Normative Aging Study [24], a longitudinal study of ageing established by the Veterans Administration in 1961. To this end, a total of 914 male volunteers, aged $41-86$ yrs, were enrolled, with a relatively large number of older individuals represented $(110(12 \%)$ subjects aged $\geqslant 70 \mathrm{yrs})$. The study clearly indicated that airway responsiveness increases with advancing age among former smokers and, to a lesser extent, among subjects who have never smoked. The lack of a significant relationship in the current smokers is presumably due to the low number of smoker subjects recruited. Interestingly, these relationships held after adjustment for pre-challenge FEV1, suggesting that the impact of age on responsiveness is not mediated by an effect on airway geometry. Since this study was carried out on a male population, some concerns about the influence of sex on the prevalence of airway hyperresponsiveness in the general population are raised; in this respect, females have been shown to exhibit a higher degree of airway responsiveness [20] because of greater susceptibility to smoking or lower baseline lung function, although other studies have failed to demonstrate a role of sex as a determinant of airway responsiveness in the general population $[23,27]$. In another study conducted on the Normative Aging Study population, 435 healthy middle-aged and older males (mean age $60.3 \pm 7.26 \mathrm{yrs}$ ) underwent methacholine bronchoprovocation challenge on an annual basis over a 3-yr follow-up interval [25]. Most $(92 \%)$ subjects who did not show an airway response to methacholine at the beginning of the study remained normoresponsive at the follow-up test, whereas $8 \%$ of normoresponsive subjects developed a mild response to the bronchoprovocation challenge after 3 yrs. In contrast, most subjects who reported a greater fall in FEV1 at the first bronchoprovocation examination showed large variability in response at follow-up (concordance 45\%). A significant increment in the dose-response slope was described with advancing age in the hyperreactive individuals. Interestingly, this change was related to increasing blood basophil count, suggesting a role of the time course of the underlying inflammatory mechanisms related to ageing. In this longitudinal analysis, smoking cessation was found to predict a decrease in airway hyperresponsiveness, indirectly suggesting that smoking habit may be a factor affecting increased airway responsiveness. The level of respiratory function, expressed as FEV1 (percentage of the predicted value), did not influence the rate of increasing airway responsiveness, perhaps due to the small changes in FEV1 during the 3-yr follow-up period.

The largest cross-sectional study addressing the prevalence of airway hyperresponsiveness in a general population was conducted in the Chinese city of Anqing [26]. A total of 10,284 subjects underwent methacholine challenge during 1995-1998. The subjects were divided into four groups according to age ( $<15$ yrs, $15-29$ yrs, 30-44 yrs and $>45$ yrs). The airway response rate was found to be highest in children and older adults. This is in agreement with the study of Hopp et al. [23], and suggests that increased airway responsiveness has a bimodal distribution across the ages.

In another study, in which methacholine challenge was performed in a total of 208 individuals aged $45-86$ yrs and living in central Manchester, a high prevalence $34.1 \%$ of participants) of airway hyperresponsiveness was reported [27]. The study showed a weak independent positive association between age and airway responsiveness. Most importantly, this relationship was shown to depend on the different parameters used to describe airway calibre in the regression analysis (FEV1, FEV1/forced vital capacity (FVC) and FVC). Indeed, the study seems to indicate that the influence of age on 
TABLE 1 Characteristics of included studies

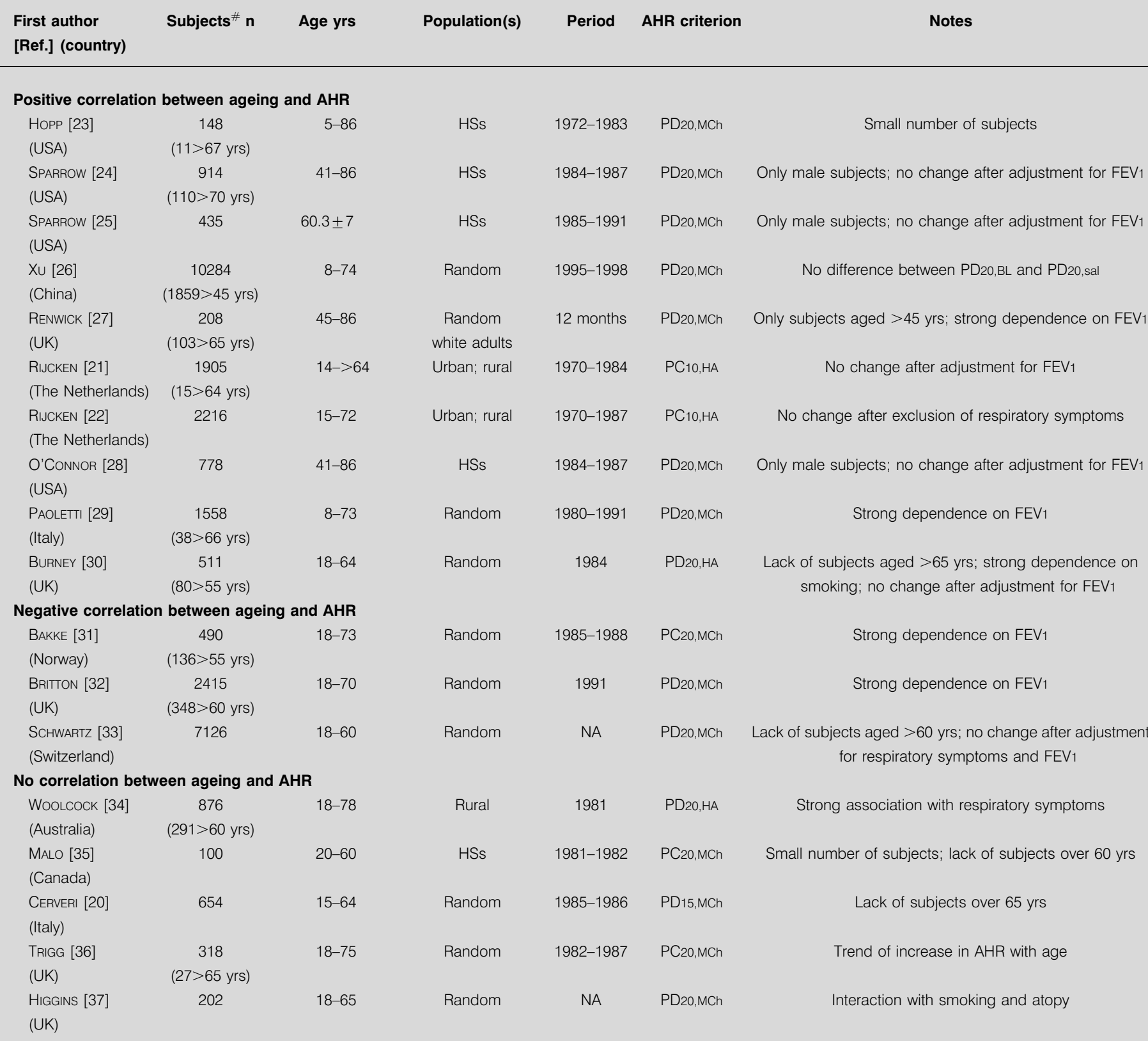

Age presented as range, or mean \pm SD when range was not accessible. AHR: airway hyperresponsiveness; HS: healthy subject; FEV1: forced expiratory volume in one second; MCh: methacholine; HA: histamine; PD20: provocative dose causing a 20\% fall in FEV1; PD20,BL: PD20 to baseline; PD20,sal: PD20 to saline; PC10: provocative concentration causing a $10 \%$ fall in FEV 1 ; PC20: provocative concentration causing a 20\% fall in FEV1; PD15: provocative dose causing a 15\% fall in FEV1; NA: not available. \#: older subjects, above specified age, given in parenthesis.

airway responsiveness is mediated by an effect on baseline airway calibre.

Taken together, these observations pose the important question as to whether baseline lung function is the main determinant of the effect of age on airway responsiveness. This issue was addressed by RIJCKEN $e t$ al. [21]. In a random population of 1,905 subjects, selected from a large-scale population study conducted in the Netherlands, airway hyperresponsiveness, assessed using the histamine challenge test, was detected in $24.5 \%$ of the sample, increasing from $13.8 \%$ in subjects aged $14-24$ yrs to $40.5 \%$ in those aged $55-$ $64 \mathrm{yrs}$. In the 15 subjects aged $>64 \mathrm{yrs}$, the percentage of positive histamine test results was 33.3. This trend was significant $\left(X^{2}=73.8\right.$ (four degrees of freedom); $\mathrm{p}<0.0001$; $\left.b=6.9 \% \cdot \mathrm{yr}^{-1}\right)$. The independent role of age was confirmed by logistic regression analysis. In order to investigate the effect of lung function on the relationship between age and airway responsiveness, the analysis was repeated with separate adjustment for FEV1, FEV1/height ${ }^{2}$, FEV1/vital capacity and 
FEV1 (\% pred), and yielded similar results. The same authors later confirmed the strong association of age with airway responsiveness by examining a sample of 2,216 subjects aged 15-72 yrs [22]. The results of the regression analysis between age and hyperresponsiveness remained unchanged when subjects with respiratory symptoms were excluded. In conclusion, older age was associated with higher airway hyperresponsiveness, independently of the level of respiratory function and/or symptoms. These results were confirmed when the responsiveness was analysed as a binary variable. Similar findings were found by $\mathrm{O}^{\prime} \mathrm{CONNOR}$ et al. [28], who reported a positive association between age and airway hyperresponsiveness, independently of FEV1 in a cohort of 778 middle-aged and elderly males (age $41-86$ yrs). PAOLETTI et al. [29] obtained methacholine bronchoprovocation challenge results from 1,558 subjects, aged $8-73$ yrs, who participated in the Po River Delta Epidemiological Study, a prospective longitudinal study on the natural history of chronic obstructive pulmonary disease. In agreement with previous observations, airway responsiveness was higher in older ages, when the population was analysed cross-sectionally, and remained unchanged when subjects with respiratory symptoms were removed.

In a randomly selected population consisting of 511 individuals, aged 18-64 yrs, from two areas in the south of England, BURNEY et al. [30] confirmed that age was independently associated with the response to histamine bronchoprovocation; the authors described the distribution of airway hyperresponsiveness as a U-shaped curve by age: the prevalence of airway hyperresponsiveness was high in the 18-24-yr study group, fell to $10 \%$ in those aged $35-44$ yrs and then rose again to $24 \%$ in those aged 55-64 yrs. The inclusion of baseline lung function in the multiple regression analysis did not alter the estimates of the regression coefficients. Conversely, smoking was the most important factor affecting hyperresponsiveness in the older subjects.

\section{Airway hyperresponsiveness is not influenced by ageing}

As previously mentioned, some studies do not confirm the positive correlation between airway hyperresponsiveness and ageing. In this context, two studies deserve some attention [31, 32]. Although showing a positive relationship between ageing and airway responsiveness, after adjustment for airway calibre (in terms of pre-test FEV1), increasing age was associated with a decreased, rather than increased, risk of hyperresponsiveness. BAKKE et al. [31] analysed a Norwegian population consisting of 490 subjects, with an age range of 18-73 yrs. Interestingly, the authors predicted that, for every $10-\mathrm{yr}$ increase in age, the adjusted odds ratio for a $\mathrm{PC} 20$ to methacholine of $<32 \mathrm{mg} \cdot \mathrm{mL}^{-1}$ decreased by two. BRITTON et al. [32] measured airway responsiveness in a population of 2,415 adults aged 18-70 yrs. Before adjustment for FEV1, the independent odds ratio for older age groups was 2.05, whereas, after adjustment for FEV1, the relationship between age and airway responsiveness reversed, such that increased age was associated with lower airway responsiveness. The implication of these observations is that normally sized airways in older individuals would be relatively unlikely to be hyperreactive. The most important findings against an effect of age on airway responsiveness are provided by the Swiss
Study on Air Pollution and Lung Disease in Adults (SAPALDIA), a multicentric study designed to examine potential associations between air pollution and lung diseases in adults [33]. A total of 7,126 subjects aged 18-60 yrs underwent bronchoprovocation challenge with methacholine. Although the study did not include subjects aged $>60 \mathrm{yrs}$, thus limiting comparison with other studies, airway responsiveness was found to decline with increasing age. In particular, the decline was markedly affected by atopic status and smoking habit; indeed, the reduction in airway responsiveness was smaller in the nonatopic categories and increased with the number of cigarettes smoked daily. Similar results were obtained when the analysis was corrected for respiratory symptoms and level of lung function.

WoOLCOCK et al. [34] assessed airway responsiveness to histamine in a rural Australian population consisting of 876 subjects (aged 18-78 yrs), and concluded that age did not affect airway hyperresponsiveness. Similarly, MALO et al. [35] and CERVERI et al. [20] did not find any relationship between age and airway hyperresponsiveness. In particular, the study performed by MALO et al. [35] included a sample of 100 nonsmoking individuals, ranging 20-60 yrs of age, with no respiratory symptoms, atopic history or familial history of asthma. This study showed that age did not induce changes in airway responsiveness, whereas baseline airway calibre appeared to be the major determinant of airway hyperresponsiveness. The study by CERVERI et al. [20] included 654 subjects from a small town in northern Italy, whose age ranged 1564 yrs. The provocative dose of methacholine causing a $15 \%$ fall in FEV1, chosen to detect airway hyperresponsiveness, did not correlate with age. However, both studies suffer from the lack of subjects aged $>65$ yrs.

TRIGG et al. [36] investigated the role of age in airway responsiveness in a general practice population of 318 subjects (aged 18-75 yrs); again, airway hyperresponsiveness was not associated with increasing age, although it could be argued that the proportion of subjects showing airway hyperresponsiveness was higher in the oldest group $(>30 \%$ in those aged $65-75$ yrs versus $\leqslant 25 \%$ in the other study groups). The study also showed a strong negative association between airway hyperresponsiveness and baseline lung function.

In a total of 202 subjects, age ranging 18-65 yrs, randomly selected from an area in eastern England, HiGGINS et al. [37] were able to demonstrate that age does not have a significant impact on airway responsiveness, although an interaction with smoking and atopy is reported. In other words, the influence of smoking and atopy on airway responsiveness could be mediated by an effect of ageing on the former. Indeed, the effects of smoking habit and atopy diminish with ageing.

\section{DISCUSSION}

The findings of the present review seem to suggest that, overall, the prevalence of airway hyperresponsiveness increases with age. It should be noted that the studies that negate the increase in airway hyperresponsiveness with ageing fail to include subjects aged $>65 \mathrm{yrs}$; indeed, in four out of eight studies that were included, the analysis is limited to subjects aged $<65 \mathrm{yrs}$, and in none of the studies are subjects aged $>80$ yrs included. Conversely, with the exception of one 
study [30], all investigations showing a positive correlation between age and airway hyperresponsiveness recruited subjects aged $>65$ yrs. Together with data provided by studies on children or adolescents (which are not shown in the present review), these observations raise the hypothesis of a U-shaped distribution of airway responsiveness, which appears to be highest in the early and late phases of life.

There is no doubt that some factors, such as the pre-test lung function state, atopic condition and smoking habit, profoundly affect the hyperresponsive condition. As a consequence, their role cannot be ignored when airway hyperresponsiveness is assessed in those of older age. Other mechanisms (e.g. inflammatory and neuronal) or technical aspects also need to be taken into account.

\section{Lung function}

Ageing per se is associated with important structural and physiological changes. The senile lung is characterised by an exaggerated but homogeneous enlargement of airspaces [17, 38, 39]. The age-dependent alterations that occur in the connective tissue of the lungs exert physiological changes in respiratory function, mainly with a reduction in the elastic recoil pressure $[18,40,41]$; since elastic recoil is considered a limiting factor for the maximum decrease in airway calibre during bronchoconstriction [42], these alterations in lung elasticity could result in enhanced bronchoconstriction. Indeed, the reduction in the elastic recoil of the lung reduces the radial traction that is applied to the airway walls, allowing for the loss of supporting tissue from peripheral airways with ease of airway closure [43], depicting a functional lung pattern that STANESCU [44] described as "small airways obstruction syndrome". As a consequence, increasing age results in a reduction in maximal expiratory flow rates and may lead to increased residual volume (RV). A condition of air trapping, expressed in an increased $\mathrm{RV} /$ total lung capacity ratio, has been demonstrated to be the best predictor of a positive methacholine bronchoprovocation result, even in subjects with normal FEV1/FVC [45]. This could explain the increased likelihood of airway hyperresponsiveness in the elderly. On this basis, it is conceivable to hypothesise that the relationship between age and increasing airway responsiveness is simply mediated by geometric factors related to changes in lung volumes and, in turn, airway calibre. Since the resistance of a tube is inversely related to its radius to the fourth power, a given degree of airway smooth muscle shortening causes a greater narrowing if the airway calibre is smaller [46] This mechanism, rather than being considered an intrinsic difference in airway responsiveness between young and elderly subjects, could be promoted as a major reason for the increased airway responsiveness that is associated with ageing. The present authors envisage that the phenomenon of increased airway hyperresponsiveness with ageing is a result of the decline in lung function associated with age-related abnormalities of the lung.

Another aspect of the association between lung mechanics and age is worth addressing, namely the effect of deep inspiration on airway calibre. Lung inflations have been demonstrated to have beneficial effects on the airways of healthy subjects [4751]. Impairment of these respiratory functions is associated with the occurrence of airway hyperresponsiveness and respiratory symptoms $[49,52]$. It has been demonstrated that the bronchodilatory effect of deep inspiration diminishes with ageing [53]. It has been hypothesised that deep inspirations induce bronchodilation by stretching the airways because of the forces of interdependence between airways and parenchyma $[46,54]$. Therefore, any factor affecting this relationship leads to impairment of the bronchodilatory ability of deep inspirations. A condition of reduced elastic recoil, such as that documented in the elderly, could reasonably account for the attenuation of deep-inspiration-induced bronchodilation. The attenuation of the ability of the respiratory system to reinstate airway patency could contribute to the occurrence of airway hyperresponsiveness with ageing, perhaps playing a central role in the development of lower respiratory symptoms in the elderly.

The question remains as to whether the smooth muscle of aged airways shows altered contractility. To the present authors' knowledge, this has not been addressed. The present original contribution to this topic is based on findings from a study that shows that the airway response to inhaled methacholine, when the deep inspiration effect is removed, does not appear to be strongly influenced by age (data not shown). Although the outcome of in vivo administration of a direct bronchoconstrictive stimulus is probably dependent on several factors, it is not unreasonable to argue that, when the lung inflation effect is removed, such as in the protocol that involves single doses of methacholine [55], the primary factor affecting the outcome of a bronchial challenge with a direct stimulus is smooth muscle reactivity. Based on this observation, the previously described changes in airway responsiveness associated with ageing cannot be attributed to alterations in the contractile state of airway smooth muscle, but might be, at least in part, related to changes in the beneficial effects of lung inflation.

\section{Smoking}

Asymptomatic smokers show increased airway responsiveness compared to nonsmokers [56]. This difference becomes more evident in elderly populations, in whom the duration of exposure to cigarette smoking is longer. Many factors have been advocated to explain the effect of smoking on airway responsiveness. These can be grouped into two main mechanisms. On the one hand, smoking can cause chronic airway inflammation and damage to the epithelium, thus leading to the development of airway hyperresponsiveness; in this context, a dose-dependent relationship between the number of cigarettes smoked and the degree of hyperresponsiveness has been demonstrated [57]. On the other hand, the increased responsiveness that is observed in current or former smokers of advanced age could occur through an effect on airway calibre. Therefore, adjustment for FEV1 is advocated when the association between cigarette smoking and airway hyperresponsiveness is to be assessed. However, after controlling for baseline lung function, the effect of smoking on airway responsiveness appears to remain, supporting the hypothesis of a direct effect of smoking on responsiveness. In support of a direct effect is the observation that increased airway responsiveness is also detected after relatively short exposure to smoking, when significant changes in lung function are not expected. Finally, an acceleration of the normal ageing 
processes after tobacco exposure, through mechanisms that are not clear, cannot be excluded. Smoking exposure could induce a low grade of inflammation of the airways that alters the responsiveness to stimuli through the release of mediators acting on airway smooth muscle.

A selection bias in the inclusion of smoking habit could explain some discrepancies between studies when assessing the effect of age on airway hyperresponsiveness. The lack of a significant association between cigarette smoking and airways hyperresponsiveness that has been observed in some studies could depend on the fact that hyperresponsive individuals tend to quit smoking. Conversely, subjects who show some degree of airway hyperresponsiveness because of exposure to passive smoking in a work environment could become normoresponsive after retirement. To the present authors' knowledge, this has not been specifically addressed.

In conclusion, cigarette smoking can be reasonably considered to be one of the main factors affecting the relationship between airway responsiveness and ageing, primarily because of the length of exposure.

\section{Sex}

Several studies have demonstrated the role of female sex as a risk factor associated with airway hyperresponsiveness [20, 29, 32]. It has been suggested that the higher prevalence of airway hyperresponsiveness in females could be attributable to their smaller lung volumes. LEYNAERT et al. [58] have confirmed the independent role of female sex in the occurrence of airway hyperresponsiveness after adjusting for height and body mass index in order to exclude the effect of anthropometric difference, and after adjusting for various spirometric parameters (FEV1, FEV1 (\% pred), FVC and FEV1/FVC) in order to abolish the effect of different airway calibre. Perhaps females are more susceptible than males to other environmental factors. In this respect, it should be noted that the use of gas for cooking is associated with a higher risk of respiratory symptoms and impaired lung function in females than in males [59]. Greater cholinergic reactivity has been observed in females [60], and hormonal differences related to sex might explain the age and sex differences in airway responsiveness. Finally, some authors have reported an association between airway hyperresponsiveness and smoking in females but not in males $[29,61]$, suggesting that females are more susceptible than males to the effect of smoking, thus developing airway hyperresponsiveness to a greater degree. Longitudinal confirmation of these findings would clarify the above-mentioned issues.

\section{Atopy}

Atopic status is one of the major factors associated with the phenomenon of airway hyperresponsiveness in the general population [62-64]. However, the role of atopy in the occurrence of airway hyperresponsiveness in the elderly is not clear. At more advanced age, atopic status appears to markedly influence development of asthma. In this respect, BurRows et al. [13] have demonstrated that the level of serum immunoglobulin (Ig) $\mathrm{E}$ is a strong predictor of new-onset asthma in a population aged $>60$ yrs. With respect to airway hyperresponsiveness, RENWICK and CONNOLLY [65], in a study performed on a random population sample of adults, have shown that the relationship between airway hyperresponsiveness and measures of atopy (IgE score and eosinophil count) becomes significant only at more advanced age ( $>65 \mathrm{yrs})$. This raises the hypothesis that discrepancies among studies could depend upon the different methods, such as skin-prick testing or total serum IgE level, that have been used to define the atopic condition. Although IgE levels and skin-prick testing are positively associated, it is not uncommon to find subjects with low levels of $\operatorname{IgE}$ and strong reactions to prick tests [66]. Some studies have found that the hyperresponsive state increases with ageing, especially among atopic subjects [62-64]. In addition, eosinophil numbers in the blood have been demonstrated to increase with ageing [22]. Taken together, these observations further support the concept that atopy can be considered an additional factor that contributes to increase the occurrence of hyperresponsiveness in individuals of this age range.

\section{Inflammatory mechanisms}

Inflammatory processes of the airways enhanced by ageing could be involved in the development of increasing nonspecific airway responsiveness with ageing. In particular, Sparrow et al. [25] have focused on the role of basophils: the authors demonstrated a correlation between annual change in basophil count and change in the methacholine dose-response slope $(p=0.02)$; after 3 yrs of follow-up, the increase in basophil count was associated with an increase in airway responsiveness.

Recently, the number of neutrophils in the lower respiratory tract of healthy elderly individuals has been evaluated. An increase in neutrophil numbers suggestive of low-grade inflammation has been documented in the airspaces of clinically normal older individuals [67]. Despite the emerging evidence of asymptomatic inflammation in aged airways, its relationship with asymptomatic airway hyperresponsiveness is not clear. The increased ability of neutrophils isolated from the elderly to produce increased amounts of elastase could play an important role in the pathogenesis of loss of elastic recoil and of elastin fibres in the ageing lung, which, in turn, would reduce the interdependence between the airways and parenchymal structures, thus contributing to airway hyperresponsiveness. Further studies should assess whether, in the elderly healthy population, the level of airway inflammation relates to the magnitude of airway hyperresponsiveness.

\section{Neuronal mechanisms}

Ageing is associated with changes in neuronal mechanisms that are implicated in the regulation of the activity of bronchial smooth muscle. It could be argued that the relationship between airway hyperresponsiveness and ageing can be explained by an age-related increase in bronchial smooth muscle contractility with age. This is a consequence of the impact of mediators that are released by the respiratory epithelium, damaged after long-term exposure to tobacco smoking or pollution. Another important factor that is cited in the literature is the imbalance between nonadrenergic inhibitory and noncholinergic excitatory fibres [68], which would lead to increased bronchial muscle tone. Conversely, biochemical factors should also be taken into consideration; indeed, some studies have demonstrated an age-related decline in $\beta$-adrenergic receptor function that causes alteration of 
autonomic control of the airways [69, 70]. This has been advocated as one of the major causes of increased airway responsiveness in the elderly. If this is true, the phenomenon of airway hyperresponsiveness could be considered an unavoidable aspect of ageing.

\section{Technical aspects}

Different deposition of the aerosol in central rather than peripheral airways, although unlikely, could, in part, explain differences in responsiveness between young and elderly individuals. This would be due to different surface exposure. In children, who have smaller airway diameters, the spasmogen is more likely to impact in the larger airways, where the highest number of receptors are present. This may result in an exaggerated central airway response to methacholine [23]. It is reasonable to hypothesise that this phenomenon would decrease with lung growth, and would, again, occur in the elderly for the above-described structural senile alterations of the lung leading to early collapse of the airways. In other words, changes in responsiveness with age could simply be due to the easier access of the spasmogen to the receptors.

In addition, a proportionally greater dose of spasmogen could impact on airway of smaller lungs, with small but significant effect on the measurement of airway responsiveness. In this respect, PEAT et al. [71] have shown that the differences in prevalence of airway hyperresponsiveness between age groups was reduced by adjusting the outcome for FVC as a surrogate measure of lung size and FEV1/FVC as a surrogate measure of airway calibre.

\section{Comments and limitations}

Several considerations from the evaluation of these studies should be taken into account. First, some discrepancies between studies may depend upon the paucity of subjects recruited aged $>65 \mathrm{yrs}$, and/or the different methods of analysis employed (such as considering airway responsiveness as a continuous versus a dichotomous variable). It is not unlikely that different levels of cooperation and understanding of the method may have had some impact on outcomes, especially in the extremely old; elderly subjects may experience fatigue or lack of interest, and their response may not be reliable. In this respect, however, experience has clearly demonstrated that elderly individuals are able to perform spirometric manoeuvres that meet American Thoracic Society criteria as well as young subjects do [72]. The possibility also exists that, when not specifically accounted for, the "respiratory symptom" variable markedly influences the relationship between age and airway responsiveness.

Since the aim of the present study was to provide a comprehensive evaluation of the relationship between airway hyperresponsiveness and ageing, a semiquantitative approach was used with the sole intent of describing the occurrence, or lack thereof, of an association between these two variables. This approach does not allow direct comparison between studies, mainly because it cannot take into account differences in age range and sample size. This limitation also arises because, although indicating the age range of the study sample, most studies do not provide information on the percentage of subjects included aged $>65$ yrs. Selection factors, such as inclusion of subjects who were motivated to participate because they experienced transient respiratory symptoms, and exclusion of subjects who were unable to attend the clinic due to disability, need to be taken into account when comparing studies. Another problem is based on the variability in defining positive responses to stimuli between different studies, in that different cut-off levels were chosen to define the condition of hyperreactivity. Direct comparison between studies is, therefore, difficult. Comparing the results of studies by calculating an annual increase in prevalence of airway hyperresponsiveness should be based on the assumption of linearity, which may not be the case. In addition, large differences in the duration of studies further limit the interpretation of the results.

\section{Clinical implications}

The clinical significance of these observations lies in the fact that the elderly population is particularly at risk of developing excessive airway narrowing, and represents one of the high-risk groups for severe asthma morbidity and asthma mortality [14]. This is confirmed by the observation that, despite comparable pulmonary function and airway hyperresponsiveness, the airways of elderly patients with asthma are more reactive than those of young asthmatics when airway responsiveness is expressed in terms of methacholine-induced changes in FVC [73]. This implies that elderly asthmatic patients are at higher risk of airway closure [74]; thus, assessing airway hyperresponsiveness by means of exaggerated reduction in FVC could help to identify these subjects. The concept of increased severity of airway hyperresponsiveness in older subjects is confirmed by the results of two studies. In the study of Hopp et al. [23], the area under the curve appeared to be smaller (higher responsiveness) in the 11 subjects whose age ranged $67-86$ yrs than that in younger age groups. In another investigation, the percentage of subjects with higher hyperresponsiveness (PC20 of $5 \mathrm{mg} \cdot \mathrm{mL}^{-1}$ ) was $11.2 \%$ in older adults (aged $45-74 \mathrm{yrs}$ ) and $6.8 \%$ in adults (aged 30-44 yrs) [26]. Taken together, it can reasonably be inferred that the severity of airway hyperresponsiveness seems to increase with ageing. A contributory factor to this phenomenon could be the progressive fall in oestrogens, which exert a relaxing effect on airway smooth muscle [75], with ageing; this inference is derived from studies in which females on postmenopausal hormone replacement therapy showed a lower prevalence of airway hyperresponsiveness than age- and weight-matched controls $[75,76]$. Obviously, this is closely associated with sex differences and additional studies are necessary before any conclusions regarding this matter can be drawn.

The clinical importance of a condition of increased prevalence and severity of airway hyperresponsiveness in elderly subjects is further enhanced by the low perception of bronchoconstriction that some individuals may experience [77]. CONNOLLY et al. [78] have demonstrated that, even in healthy subjects, elderly individuals experience less awareness of bronchoconstriction during methacholine bronchoprovocation, despite similar degrees of bronchoconstriction. This observation has been confirmed by a recent study on elderly asthmatics [77]. The presence of one or more comorbid conditions, which become common in the elderly [79], significantly affects the quality of life in this population [80, 81], thus contributing to further 
impair perception of bronchoconstriction, especially in the extremely old, in whom multiple comorbid conditions are the rule. From a clinical perspective, it is conceivable to envisage a scenario in which, for the same degree of hyperresponsiveness, older individuals would not complain of wheezing, and the condition of unrecognised airway hyperresponsiveness could lead to the occurrence of severe airway narrowing. Hence the need for the physician to be alerted regarding potential underlying hyperresponsiveness of the airways. Primary care physicians should be encouraged to ask about the presence of complaints that are suggestive of airway hyperresponsiveness in elderly patients: most elderly subjects who are diagnosed with asthma report wheezing symptoms many years before the diagnosis [13]. When indicated, methacholine bronchoprovocation could permit early identification of this condition, thus contributing to the prevention of fatal respiratory events.

In terms of prevention, active intervention would aim, when appropriate, at reducing body weight; high body mass index has been associated with increased airway responsiveness in elderly subjects [82]. Although the prevalence of obesity decreases with advanced age, it remains a common problem in the elderly [83], mainly because of reduction in physical activity and decrease in energy expenditure, which predispose to fat accumulation and redistribution. Body weight increases should be taken into consideration by primary care physicians and, consequently, prevention and treatment programmes should be applied in the same way as in younger populations. The choice of whether pharmacological treatment should be initiated in these subjects remains a matter of discussion. Although inhaled corticosteroids are known to induce a significant reduction in airway hyperresponsiveness [84], longitudinal data on their effect on clinical outcomes are scarce [85, 86]. These limitations do not justify their application at present.

\section{Conclusions}

Airway hyperresponsiveness is common in the general population and is associated with an increased risk of developing respiratory symptoms and with an accelerated decline in lung function. The pathogenesis of increased airway responsiveness, however, remains uncertain. Some factors have been identified as important determinants of the occurrence or worsening of reactivity; among these, pre-test reduced lung function and a history of smoking exposure are the main predictors of greater responsiveness. The role of these factors is amplified at more advanced age, because of the agerelated changes in lung function and the length of exposure to pollutants. The importance of this phenomenon in the elderly population is highlighted by the recent observation that, independently of smoking habit or low lung function, increased airway responsiveness is directly associated with increased mortality among chronic obstructive pulmonary disease individuals [87]. The clinical significance of these observations lies in the fact that the elderly population is particularly at risk of developing persistent airway closure. The important question is, therefore, whether measurements of airway hyperresponsiveness are valuable in elderly individuals, in whom the perception of symptoms may be blunted. The present authors propose that assessment of airway hyperresponsiveness in the elderly should be considered an additional tool in the diagnostic work-up of subjects who belong to the at risk group, such as those with long-term smoking exposure and/or documented atopy.

\section{ACKNOWLEDGEMENTS}

The authors wish to thank R. Antonelli-Incalzi for helpful suggestions regarding the interpretation of the findings.

\section{REFERENCES}

1 National Asthma Education and Prevention Program. Expert Panel Report: Guidelines for the Diagnosis and Management of Asthma. Update on Selected Topics - 2002. J Allergy Clin Immunol 2002; 110: Suppl. 5, S141-S219.

2 Boulet LP. Asymptomatic airway hyperresponsiveness: a curiosity or an opportunity to prevent asthma? Am J Respir Crit Care Med 2003; 167: 371-378.

3 Laprise C, Boulet LP. Asymptomatic airway hyperresponsivness: a three-year follow-up. Am J Respir Crit Care Med 1997; 156: 403-409.

4 Vollmer WM, Johnson LR, Buist AS. Relationship of response to a bronchodilator and decline in forced expiratory volume in one second in population studies. Am Rev Respir Dis 1985; 132: 1186-1193.

5 Lange P, Parner J, Vestbo J, Schnour P, Jensen GA. 15-year follow-up study of ventilatory function in adults with asthma. N Engl J Med 1998; 339: 1194-1200.

6 Parker DR, O'Connor GT, Sparrow D, Segal MR, Weiss ST. The relationship of nonspecific airway responsiveness and atopy to the rate of decline of lung function. The Normative Aging Study. Am Rev Respir Dis 1990; 141: 589-594.

7 O'Connor G, Sparrow D, Weiss S. A prospective longitudinal study of methacholine airway responsiveness as a predictor of pulmonary-function decline: the Normative Aging Study. Am J Respir Crit Care Med 1995; 152: 87-92.

8 Ten Hacken NH, Postma DS, Timens W. Airway remodeling and long-term decline in lung function in asthma. Curr Opin Pulm Med 2003; 9: 9-14.

9 Horsley JR, Sterling IJ, Waters WE, Howell JB. How common is increased airway reactivity amongst the elderly? Gerontology 1993; 39: 38-48.

10 Choy DK, Hui DS, Li ST, et al. Prevalence of wheeze, bronchial hyper-responsiveness and asthma in the elderly Chinese. Clin Exp Allergy 2002; 32: 702-707.

11 Connolly MJ, Kelly C, Walters EH, Hendrick DJ. An assessment of methacholine inhalation tests in elderly asthmatics. Age Ageing 1988; 17: 123-128.

12 Tracey M, Villar A, Dow L, Coggon D, Lampe FC, Holgate ST. The influence of increased bronchial responsiveness, atopy, and serum IgE on decline in FEV1. A longitudinal study in the elderly. Am J Respir Crit Care Med 1995; 151: 656-662.

13 Burrows B, Lebowitz M, Barbee R, Cline M. Findings before diagnoses of asthma among the elderly in a longitudinal study of a general population sample. J Allergy Clin Immunol 1991; 88: 870-877.

14 Dow L. The diagnosis of asthma in older people. Clin Exp Allergy 1994; 24: 156-159.

15 Nejjari C, Tessier JF, Barberger-Gateau P, Jacqmin H, Dartigues JF, Salamon R. Functional status of elderly 
people treated for asthma-related symptoms: a population based case-control study. Eur Respir J 1994; 7: 1077-1083.

16 Cooreman J, Segala C, Henry C, Neukirch F. Trends in asthma-induced mortality in France from 1970-90. Tuber Lung Dis 1994; 75: 182-187.

17 Verbeken EK, Cauberghs M, Mertens I, Clement J, Lauweryns JM, Van de Woestijne KP. The senile lung: comparison with normal and emphysematous lungs. 1. Structural aspects. Chest 1992; 101: 793-799.

18 Janssens JP, Pache JC, Nicod LP. Physiological changes in respiratory function associated with ageing. Eur Respir J 1999; 13: 197-205.

19 Bellia V, Battaglia S, Catalano F, et al. Aging and disability affect misdiagnosis of COPD in elderly asthmatics: the SARA study. Chest 2003; 123: 1066-1072.

20 Cerveri I, Bruschi C, Zoia MC, et al. Distribution of bronchial nonspecific reactivity in the general population. Chest 1988; 93: 26-30.

21 Rijcken B, Schouten JP, Weiss ST, Speizer FE, van der Lende R. The relationship of nonspecific bronchial responsiveness to respiratory symptoms in a random population sample. Am Rev Respir Dis 1987; 136: 62-68.

22 Rijcken B, Schouten JP, Mensinga TT, Weiss ST, De Vries K, Van der Lende R. Factors associated with bronchial responsiveness to histamine in a population sample of adults. Am Rev Respir Dis 1993; 147: 1447-1453.

23 Hopp RJ, Bewtra A, Nair NM. The effect of age on methacholine response. J Allergy Clin Immunol 1985; 76: 609-613.

24 Sparrow D, O'Connor GT, Rosner B, Segal MR, Weiss ST. The influence of age and level of pulmonary function on nonspecific airway responsiveness. The Normative Aging Study. Am Rev Respir Dis 1991; 143: 978-982.

25 Sparrow D, O'Connor GT, Rosner B, Weiss ST. Predictors of longitudinal change in methacholine airway responsiveness among middle-aged and older men: the Normative Aging Study. Am J Respir Crit Care Med 1994; 149: 376-381.

$26 \mathrm{Xu} \mathrm{X}$, Niu T, Chen C, et al. Association of airway responsiveness with asthma and persistent wheeze in a Chinese population. Chest 2001; 119: 691-700.

27 Renwick DS, Connolly MJ. The relationship between age and bronchial responsiveness: evidence from a population survey. Chest 1999; 115: 660-665.

28 O'Connor GT, Sparrow D, Segal MR, Weiss ST. Smoking, atopy, and methacholine airway responsiveness among middle-aged and elderly men. The Normative Aging Study. Am Rev Respir Dis 1989; 140: 1520-1526.

29 Paoletti P, Carrozzi L, Viegi G, et al. Distribution of bronchial responsiveness in a general population: effect of sex, age, smoking, and level of pulmonary function. Am J Respir Crit Care Med 1995; 151: 1770-1777.

30 Burney PGJ, Britton JR, Chinn S. Descriptive epidemiology of bronchial reactivity in an adult population: results from a community study. Thorax 1987; 42: 38-44.

31 Bakke PS, Baste V, Gulsvik A. Bronchial responsiveness in a Norwegian community. Am Rev Respir Dis 1991; 143: 317-322.

32 Britton J, Pavord I, Richards K, et al. Factors influencing the occurrence of airway hyperreactivity in the general population: the importance of atopy and airway calibre. Eur Respir J 1994; 7: 881-887.

33 Schwartz J, Schindler C, Zemp E, et al. Predictors of methacholine responsiveness in a general population. Chest 2002; 122: 812-820.

34 Woolcock AJ, Peat JK, Salome CM. Prevalence of bronchial hyperresponsiveness and asthma in a rural adult population. Thorax 1987; 42: 361-368.

35 Malo JL, Pineau L, Cartier A, Martin RR. Reference values of the provocative concentrations of methacholine that cause $6 \%$ and $20 \%$ changes in forced expiratory volume in one second in a normal population. Am Rev Respir Dis 1983; 128: 8-11.

36 Trigg CJ, Bennett JB, Tooley M, Sibbald B, D'Souza MF, Davies RJ. A general practice based survey of bronchial hyperresponsiveness and its relation to symptoms, sex, age, atopy, and smoking. Thorax 1990; 45: 866-872.

37 Higgins BG, Britton JR, Chinn S, Lai KK, Burney PG, Tattersfield AE. Factors affecting peak expiratory flow variability and bronchial reactivity in a random population sample. Thorax 1993; 48: 899-905.

38 Saetta M, Ghezzo H, Kim WD, et al. Loss of alveolar attachments in smokers. Am Rev Respir Dis 1985; 132 894-900.

39 Lang M, Gillooly M, Stewart J, Hulmes D, Lamb D. Collagen content of alveolar wall tissue in enphysematous and non enphysematous lungs. Thorax 1994; 49: 319-326.

40 Verbeken EK, Cauberghs M, Mertens I, Clement J, Lauweryns JM, Van de Woestijne KP. The senile lung. Comparison with normal and emphysematous lungs. 2. Functional aspects. Chest 1992; 101: 800-809.

41 Permutt S, Martin HB. Static pressure-volume characteristics of lungs in normal males. J Appl Physiol 1960; 15: 819-825.

42 Ding D, Martin J, Macklem P. Effects of lung volume on maximal methacholine-induced bronchoconstriction in normal humans. J Appl Physiol 1987; 62: 1324-1330.

43 Cheung D, Schot R, Zwinderman A, Zagers H, Dijkman J, Sterk P. Relationship between loss in parenchymal elastic recoil pressure and maximal airway narrowing in subjects with $\alpha_{1}$-antitrypsin deficiency. Am J Respir Crit Care Med 1997; 155: 135-140.

44 Stanescu D. Small airways obstruction syndrome. Chest 1999; 116: 231-233.

45 Stanbrook MB, Chapman KR, Kesten S. Gas trapping as a predictor of positive methacholine challenge in patients with normal spirometry results. Chest 1995; 107: 992-995.

46 Moreno RH, Hogg JC, Pare PD. Mechanics of airway narrowing. Am Rev Respir Dis 1986; 133: 1171-1180.

47 Wheatley J, Pare P, Engel L. Reversibility of induced bronchoconstriction by deep inspiration in normal and asthmatic subjects. Eur Respir J 1989; 2: 331-339.

48 Brusasco V, Crimi E, Barisione G, Spanevello A, Rodarte J, Pellegrino R. Airway responsiveness to methacholine: effects of deep inhalations and airway inflammation. J Appl Physiol 1999; 87: 567-573.

49 Kapsali T, Permutt S, Laube B, Scichilone N, Togias A. Potent bronchoprotective effect of deep inspiration and its absence in asthma. J Appl Physiol 2000; 89: 711-720.

50 Scichilone N, Kapsali T, Permutt S, Togias A. Deep inspiration-induced bronchoprotection is stronger than 
bronchodilation. Am J Respir Crit Care Med 2000; 162: 910-916.

51 Brown RH, Scichilone N, Mudge B, Diemer FB, Permutt S, Togias A. High-resolution computed tomographic evaluation of airway distensibility and the effects of lung inflation on airway caliber in healthy subjects and individuals with asthma. Am J Respir Crit Care Med 2001; 163: 994-1001.

52 Scichilone N, Marchese R, Minà C, et al. Asthma severity is related to the bronchodilatory effect of deep inspiration (DI). Am J Respir Crit Care Med 2002; 167: A181.

53 Scichilone N, Marchese R, Catalano F, Togias A, Vignola AM, Bellia V. The bronchodilatory effect of deep inspiration diminishes with aging. Respir Med 2004; 98: 838-843.

54 Mead J, Takishima T, Leith D. Stress distribution in lungs: a model of pulmonary elasticity. J Appl Physiol 1970; 28: 596-608.

55 Scichilone N, Permutt S, Togias A. The lack of the bronchoprotective and not the bronchodilatory ability of deep inspiration is associated with airway hyperresponsiveness. Am J Respir Crit Care Med 2001; 163: 413-419.

56 Jensen EJ, Dahl R, Steffensen F. Bronchial reactivity to cigarette smoke in smokers: repeatability, relationship to methacholine reactivity, smoking and atopy. Eur Respir J 1998; 11: 670-676.

57 Gerrard JW, Cockcroft DW, Mink JT, Cotton DJ, Poonawala R, Dosman JA. Increased nonspecific bronchial reactivity in cigarette smokers with normal lung function. Am Rev Respir Dis 1980; 122: 577-581.

58 Leynaert B, Bousquet J, Henry C, Liard R, Neukirch F. Is bronchial hyperresponsiveness more frequent in women than in men? A population-based study. Am J Respir Crit Care Med 1997; 156: 1413-1420.

59 Jarvis D, Chinn S, Sterne J, Luczynska C, Burney P, on behalf of the European Community Respiratory Health Survey. The association of respiratory symptoms and lung function with the use of gas for cooking. Eur Respir J 1998; 11: 651-658.

60 Zamel N. Threshold of airway response to inhaled methacholine in healthy men and women. J Appl Physiol 1984; 56: 129-132.

61 Tashkin DP, Altose MD, Bleecker ER, et al. The Lung Health Study: airway responsiveness to inhaled methacholine in smokers with mild to moderate airflow limitation. The Lung Health Study Research Group. Am Rev Respir Dis 1992; 145: 301-310.

62 Crockcroft DW, Murdock KY, Berscheid BA. Relationship between atopy and bronchial responsiveness to histamine in a random population. Ann Allergy 1984; 53: 26-29.

63 Clough JB, Williams JD, Holgate ST. Effect of atopy on the natural history of symptoms, peak expiratory flow, and bronchial responsiveness in 7- and 8-year-old children with cough and wheeze. A 12-month longitudinal study. Am Rev Respir Dis 1991; 143: 755-760.

64 Witt C, Stuckey MS, Woolcock AJ, Dawkins RL. Positive allergy prick tests associated with bronchial histamine responsiveness in an unselected population. J Allergy Clin Immunol 1986; 77: 698-702.

65 Renwick DS, Connolly MJ. Persistence of atopic effects on airway calibre and bronchial responsiveness in older adults. Age Ageing 1997; 26: 435-440.
66 Holford-Strevens V, Warren P, Wong C, Manfreda J. Serum total immunoglobulin E levels in Canadian adults. J Allergy Clin Immunol 1984; 73: 516-522.

67 Meyer KC, Rosenthal NS, Soergel P, Peterson K. Neutrophils and low-grade inflammation in the seemingly normal aging human lung. Mech Ageing Dev 1998; 104: 169-181.

68 Barnes P. Neural control of human airways in health and disease. Am Rev Respir Dis 1986; 134: 1289-1314.

69 Vestal R, Wood A, Shand D. Reduced beta-adrenoceptor sensitivity in the elderly. Clin Pharmacol Ther 1979; 26: 181-186.

70 Heinsimer JA, Lefkowitz RJ. The impact of aging on adrenergic receptor function: clinical and biochemical aspects. J Am Geriatr Soc 1985; 33: 184-188.

71 Peat J, Salome C, Xuan W. On adjusting measurements of airway responsiveness for lung size and airway caliber. Am J Respir Crit Care Med 1996; 154: 870-875.

72 Bellia V, Pistelli R, Catalano F, et al. Quality control of spirometry in the elderly - the SA.R.A. study. Am J Respir Crit Care Med 2000; 161: 1094-1100.

73 Cuttitta G, Cibella F, Bellia V, et al. Changes in FVC during methacholine-induced bronchoconstriction in elderly patients with asthma. Chest 2001; 119: 1685-1690.

74 Macklem P. Mechanical factors determining maximum bronchoconstriction. Eur Respir J 1989; 2: Suppl. 6, 516s519s.

75 Mueller JE, Frye C, Brasche S, Heinrich J. Association of hormone replacement therapy with bronchial hyperresponsiveness. Respir Med 2003; 97: 990-992.

76 Lieberman D, Kopernic G, Porath A, Levitas E, Lazer S, Heimer D. Influence of estrogen replacement therapy on airway reactivity. Respiration 1995; 62: 205-208.

77 Joo JH, Lim GI, Seo MJ, et al. Perception of wheezing in the elderly asthmatics. Korean J Intern Med 2001; 16: 260-264.

78 Connolly MJ, Crowley JJ, Charan NB, Nielson CP, Vestal RE. Reduced subjective awareness of bronchoconstriction provoked by methacholine in the elderly asthmatic and normal subjects as measured on a simple awareness scale. Thorax 1992; 47: 410-413.

79 van Manen JG, Bindels PJ, Ijzermans CJ, van der Zee JS, Bottema BJ, Schade E. Prevalence of comorbidity in patients with a chronic airway obstruction and controls over the age of 40. J Clin Epidemiol 2001; 54: 287-293.

80 Wijnhoven HA, Kriegsman DM, Hesselink AE, de Haan M, Schellevis FG. The influence of co-morbidity on healthrelated quality of life in asthma and COPD patients. Respir Med 2003; 97: 468-475.

81 Antonelli Incalzi R, Pistelli R, Imperiale C, Catalano F, Scichilone N, Bellia V, on behalf of the Sa.R.A. Study Group. Effects of chronic airway disease on health status of geriatric patients. Aging Clin Exp Res 2004; 16: 26-33.

82 Litonjua AA, Sparrow D, Celedon JC, DeMolles D, Weiss ST. Association of body mass index with the development of methacholine airway hyperresponsiveness in men: the Normative Aging Study. Thorax 2002; 57: 581-585.

83 Kennedy RL, Chokkalingham K, Srinivasan R. Obesity in the elderly: who should we be treating, and why, and how? Curr Opin Clin Nutr Metab Care 2004; 7: 3-9. 
84 Currie GP, Fowler SJ, Lipworth BJ. Dose response of inhaled corticosteroids on bronchial hyperresponsiveness: a meta-analysis. Ann Allergy Asthma Immunol 2003; 90: 194-198.

85 Haahtela T. The long-term influence of therapeutic interventions in asthma with emphasis on inhaled steroids and early disease. Clin Exp Allergy 1998; 28: Suppl. 5: 133-140, discussion: 171-173.
86 Ward C, Pais M, Bish R, et al. Airway inflammation, basement membrane thickening and bronchial hyperresponsiveness in asthma. Thorax 2002; 57: 309316.

87 Hospers JJ, Postma DS, Rijcken B, Weiss ST, Schouten JP. Histamine airway hyper-responsiveness and mortality from chronic obstructive pulmonary disease: a cohort study. Lancet 2000; 356: 1313-1317. 